We have now followed the course of the blocks along a continuous distance of 84 geographical miles-viz. 48 on the mainland and 36 on the shores of fjords and sounds.

From what I have advanced here as regards the blocks during their journey through the Balsfjord, it seems clear that their transport here cannot be ascribed to a moving stream of inland ice. The sharp line of demarcation, above which no blocks are found, seems in itself to demonstrate this. The line extending for miles along a long fjord and extensive sounds, and being so sharply defined, bespeaks that the transporting agency at work here must have been far more regular during a length of time than a stream of inland ice possibly could be. We have therefore every reason to conclude that these blocks have been carried along the level of the sea on drift-ice, i.e. shore-ice. As the block-transport appears from the first simultaneously along the long stretch of shore from the Balsfjord, and past the Troms Island, a strong in- and outflowing current during the diurnal tides has in all probability been at work at a period when the level of the sea was 120 feet higher than at present. And the strong drift of the ice outwards must have been stronger than the one inwards up the fjord. Travelled blocks of the Kval Island granite are, therefore, not found in the interior of the fjord, but the case is different along the broad sounds about the mouth of the fjord ; here the in-and outflowing currents have had alternate sway, and here are also found blocks of the Divi Valley, as well' as of the coast granite.

There is another important circumstance which beyond a doubt proves that the inland ice during the Glacial age cannot have moved along' this fjord, scouring the bottom. Thus, if we consider the present depth, about 6 co feet, and remember that the level of the sea during the Glacial age was about 600 feet higher than at present, and further that great quantities of débris must have been deposited at the bottom of the ice, it is evident that an ice-stream moving through the fjord, and a sixth part of whose volume rose above the then sea-level, must have reached several hundred feet above the former-that is, the outgliding stream must have reached several hundred feet above 120 feet, the line of demarcation for the blocks, as it then lay at least 200 feet below the sea. If, however, this had been the case, granite blocks should now be found at a far greater height than 120 feet. Neither can the Balsfjord during the Glacial age have formed a valley along which the inland ice might move, as, in this case, travelled blocks would have been found along the sides at even far greater heights.

I have, therefore, after the most careful researches here, yard by yard, and extending over many years, come to the conclusion that the Balsfjord is not of glacial origin, but formed an incision or depression in the mountains of older origin than the Glacial age. And this conclusion I believe may, in the main, apply to the question of the formation of all fiords in the nerth of Norway. But whether it is applicable to all fjords in the whole of Norway I shall not attempt to answer.

There may, however, be reason to assume that the explanation of the fjord-formation in parts which have lain under an earlier Glacial age as being of glacial origin, is rather based on speculation than such careful and minute researches as those I have referred to here, and which may, perhaps, contribute to prove the correct theory.

Tromsö Museum

KARL PETTERSEN

\section{VARIABLE STARS}

TH IIS catalogue may be regarded as complemental to the "Catalogue of Known Variable Stars," by the same author, which was read before the Royal Irish

I A Catalogue of Suspected Variable Stars, with Notes and Observations, by J. E. Gore, M.R.I.A., F.R.A.S. A paper read before the Royal Irish Academy, May 12,1884 .
Academy, January 28, 1884. It contains a list, including lettered numbers, of 745 stars in which some change of magnitude is suspected. The stars are tabulated in order of Right Ascension for the epoch $1880^{\circ}$, and in separate columns are to be found particulars of - the supposed change of magnitude and the authority on which the sup posed change rests. In the "Notes and Observations" by which the Catalogue is followed are given particulars of the history of each star, together with observations by the author of such stars as have received attention from him. The work is accompanied by a map.showing the distribution of known and suspected variable stars.

A catalogue of this character forms a valuable working catalogue for the observer's use. By further observation suspected variation will in some cases be proved to be real, and the stars claim a place in a catalogue of known variables. A claim of this kind might indeed already be made in the case of Nos. 234,455 , and 635 of Mr. Gore's list. It may just be mentioned in passing that the place of No. 234, U Canis Minoris, is incompletely given in the Catalogue. Its more exact place for 1880 is R.A. 7h. $34 \mathrm{~m}$. 49s., Decl. $+8^{\circ} 39^{\prime} \cdot 5$. There are other cases in which, though the period is as yet indeterminate, the fact of variation and its amount may be stated with some confidence. On the other hand further observation may tend to throw a doubt on the suspicion of change in the case of other stars, and (as our author observes) "these must of course be removed from future catalogues." In the notes to No. 287 of his Catalogue a Hydræ, Mr. Gore quotes remarks by Sir John Herschel, Dr. Schmidt, and Dr. Gould to the effect that the supposed variability of this star may possibly be due to the influence of its ruddy colour on the estimates of its brightness. Is it not possible that the effect of colour on estimates of magnitude as respects different observers, or the same observer at different times, has hardly received so much attention as it deserves?

Large as is the number of stars included in Mr. Gore's Catalogue, further additions might be made to it. Comparing it, for instance, with the Table of Suspected Variables extracted from Mr. Chandler's unpublished Catalogue by Prof. Pickering, and printed in his " Recent Observations of Variable Stars" in the Proceedings of the American Academy, we find some 30 stars which are not included in Mr. Gore's list, and it is probable that others might be found in other quarters also. Indeed the experience of most variable star observers would probably suggest the view that cases of slight but distinctly recognisable light variation are relatively numerous.

A word in regard to No. 445 in the Catalogue may possibly help to avert the chance of a little confusion in the future. This star was entered as $U$ Bootis in Prof. Schönfeld's first Catalogue of Variable Stars, but was rejected by him in his "Zweiter Catalog." There is another star called U Bootis by Mr. Baxendell in a paper in the Manchester Lit. and Phil. Soc. Proceedings, vol. xxi. No. II, the place of which, brought up to I880, is R.A. I 4 h. $48 \mathrm{~m} .47 \mathrm{~s} .$, Decl. $+18^{\circ} 10^{\prime} \cdot 9$. This star has a period of $175^{\circ} 5$ days, with a range of magnitude from about 13.5 at minimum to about 9.2 at maximum.

In conclusion we commend to the attention of all who are interested in the subject of variable stars a work the preparation of which must have entailed on the author a considerable amount of labour both as compiler and observer.

\section{NOTES}

A BerLin telegram announces the sudden death of Dr. Emil Riebeck, at Feldkirch, where he was preparing for another five years' journey. Our first review in this week's NATURE refers to some of the last results of Dr. Riebeck's journeys. Either directly or indirectly he has done good work for science in 